\title{
RASIO KEMAMPULABAAN DALAM MENGUKUR KINERJA MANAJEMEN KOPERASI PADA KUD “KARYA MUDA DI DESA MENINTING KECAMATAN BATU LAYAR KABUPATEN LOMBOK BARATTAHUN 2014-2018
}

\author{
Oleh \\ Suamdi $^{1}$ \& Jmawan Aii ${ }^{2}$ \\ 1,2Sekolah Tinggi ilmu Ekonomi 45 Mataram \\ Email: ${ }^{1}$ andliinda196263@gmail.com \& ${ }^{2}$ joemhero@gmail.com
}

\begin{abstract}
Abstrak
Kinerja manajemen koperasi dapat diukur dari rasio kemampulabaan adalah untuk mengukur tingkat efektifitas manajemen dalam mengelola asset dan equity yang dimiliki koperasi.untuk menghasilkan laba yaitu sisa hasil usaha (SHU). Pengelolaan modal tidak mudah karena pada koperasi sangat tergantung pada keputusan rapat anggota tahunan (RAT). Seringkali terjadi piutang yang tidak tertagih , inilah risiko kredit. Karena koperasi mempunyai kecendrungan social oriented , daripada profit oriented. Sesuai dengan hasil RAT. Kesepakatan yang terpenting memnuhi harapan untuk kesejahtraan anggota. Pada koperasi Unit Desa Karya Muda, Desa Meninting Kecamatan Batu Layar Kabupaten Lombok Barat adalah milik masyarakat desa Kesulitan pengelola dalam menagih piutang dapat berdampak terhadap kemampuan koperasi untuk menghasilkan laba. Karena perputaran modal tidak lancar. Karena itu perlu dianalisis rasio kemampulabaan dari laporan keuangan koperasi. Hasil penelitian dalam 5 tahun terakhir dari tahun 2014 sampai dengan tahun 2018 adalah rata-rata. Gross Profit ratio sebesar 21,30 \%. Dan rata-rata Return On Invesment ratio sebesar 5,97 \%.. Dapat disimpulkan bahwa kinerja manajemen koperasi ditinjau dari rasio kemampulabaan adalah efektif berada diatas rata-rata tingkat suku bunga deposito bank yang berlaku yaitu rata-rata 5,7\% per tahun. Disarankan kepada manajemen, modal usaha dikelolala secara efektif ,.agar SHU yang dihasilkan lebih tinggi dan ditingkatkan. Juga direkomendasikan kepada peneliti lain untuk menganalisis efisiensi operasi manajemen
\end{abstract}

Kata Kunci : efektifitas, pengelolaan, asset \& equity

\section{PENDAHUALUAN}

\section{Koperasi sebagai soko guru dalam tatanan perekonomian berbasis ekonomi} kerakyatan. Tujuannya untuk mewujudkan kesejahtraan anggota pada khususnya dan masyarakat pada umumnya. Dalam menjadikan tujuan dapat tercapa,i apabila mengelola dari asset dan sumber daya manusia secara efektif dan efisien. Koperasi saat ini tidak boleh sekedar tumbuh bagaikan jamur di musim hujan. Hanya untuk sekedar organisasi bersifat social oriented akan tetapi juga profit oriented. Agar dapat mewujudkan kesejahtraan anggota. Akan tetapi tidak mengurangi atau melemahkan hasil keputusan tertinggi yaitu rapat anggota tahunan (RAT), karena inilah salah satu keunikan dari badan usaha yang berbentuk koperasi. Hasil RAT merupakan hasil yang mufakat dan musyawarah. http://ejurnal.binawakya.or.id/index.php/MBI
Dalam era globalisasi koperasi harus memilki daya saing. Tidak bisa dipungkiri bahwa semakin pesatnya perkembangan dan kemajuan perekonomian dunia. Dan teknologi semakin maju maka tantangan bagi koperasi, untuk memikirkan kemajuan koperasi yang di kelolanya. Dalam pengelolaan koperasi banyak faktor yang berpengaruh dalam kelancaran dan keberhasilannya. Oleh karena itu kegiatan seluruh manajemen harus bersinergi anatara kegiatan manajemen SDM,manajemen keuangan, manajemen pemasara, manajemen operasional. Kegiatan tersebut harus saling menunjang dan bersama-sama dalam menghadapi tantangan bisnis.Satu sama lain tidak dapat dipisahkan. Sehingga pengurus koperasi dapat melakukan pengelolaan dengan baik. Penelitian ini membatasi pada permasalahn

Vol.13 No.9 April 2019

\section{Open Journal Systems}


kinerja manajemen dalam mencapai efektifitas penggunaan modal ditinjau dari rasio kemampulabaan atau rasio keuntungan arau sering disebut rasio profitabilitas.

Rasio profitabilitas adalah rasio-rasio yang menunjukkanhasil akhir dari sejumlah kebijaksanaan dan keputusan-keputusan profit margin, gross profit margin, Return on total asset , return On Invesment, dan lain-lain).(Bambang Riyanto;2011:331) Artinya bahwa dalam mengelola permodalan koperasi maka alat analisis ini dipergunakan untuk mengetahui kemampuan koperasi dalam mengelola modalnya dalam menghasilkan SHU. Karena rasio ini dapat dipergunakan untuk mengetahui berapa besar hasil yang didapat oleh koperasi dalam mengatur keuangannya atau modal yang didapat dari anggota koperasi berupa simpanan pokok,simpanan wajb ,simpanan sukarela dan dana hibah maupun dana donator dan pinjaman jangka pendek maupun jangka menengah dan jangka panjang dan cadangan modal yang dianggap sebagai modal usaha dari koperasi. Modal yang dihimpun dan didistribusikan kembali keoada anggota koperasi maupun non anggota.Sesuai dengan tujuannya bahwa koperasi dapat mensejahtrakan anggota pada khususnya dan masyarakatpada umumnya. Tetapi selalu juga berprinsip untuk dapat memperluas usaha secara otomatis berharap mendapat SHU yang tinggi. Untuk kelanjutan dari koperasi tersebut.

Dalam kumpulan artikel pendidikan bahwa : Keunggulan analisis rasio keuangan yang mencakup alisis rasio keuangan , analisis kelemahan dan kekuatan di bidang finansial akan sangat membantu dalam menilai perestasi manajemen dimasa lalu dan prospeknya di masa mendatang. Dengan analisis keuangan ini dapat diketahui kekutan serta kelemahan yang dimilki oleh seorang business enterprise. Rasio tersebut dapat memberikan indikasi apakah perusahaan memiliki kas yang cukup untuk memenuhi kewajiban finansiilnya, besarnya piutang yang cukup rasional, efisiensi manajemen persediaan, perencanaan pengeluaran investasi yang baik, dan struktur modal yang sehat sehingga tujuan memaksimumkan kemakmuran pemegang saham dapat tercapai. Dengan menganalisis prestasi keuangan , seorang analis keuangan dapat merencanakan dan mengimplementasikan kedalam setiap tindakan secara konsisten dengan tujuan memaksimumkan kemakmuran pemegang saham. Disamping itu analisis semacam ini juga dapat dipergunakan oleh pihak lain seperti bank, untuk menilai apakah cukup beralasan (layak) untuk memberikan tambahan dana atau kredit baru, calon investor untuk memproyeksikan prospek perusahaan di masa yamg akan datang (R.Agus Sartono,1994 :119-120) Serta kelemahan Analisis rasio Keuangan menurut Teuku Mirza dan Imbuh S. (1999), ada beberapa : 1. Adanya distorsi karena laba yang dimasukkan tidak memasukkan unsur biaya modal ekuitas. 2 . Laporan keuangan dari suatu perusahaan yang memiliki sejumlah divisi dari industry yang berlainan akan sulit dibandingkan dengan perusahaan lain atau dengan data suatu industry. 3. Terjadinya distorsi inflasi dan penggunaan data historis dalam akuntansi. 4. Laporan keuangan tidak dapat berdiri sendiri tetapi harus didukung oleh catatan tas laporan keuangan informasi ini harus dicermati karena mungkin memuat potensi masalah yang dapat sangat mempengaruhi kondisi keuangan suatu perusahaan. 5. Kesulitan dalammenginterpretasikan hasil analisa. Misalkan quick ratio yang tinggi apakah bagus karena kuatnya likuiditas perusahaan, atau justru jelek karena perusahaan memegang kas uyang berlebih yang justru tidak produktif. 6 . Perbedaan dalam perlakuan akuntansi dapat menimbulkan distorsi dalam membandingkan rasio. 7. Adanya praktek window dewssing tentunya membuat laporan keuangan terlihat bagus

Penelitian ini dilakukan pada KUD KARYA MUDA , Desa Meninting . Berkaitan dengan pendapat diatas pada point 5. Bahwa rasio kewajiban lancar yang berlebihan akan dapat mengakibatkan kas menganggur atau tingkat piutang yang tinggi dan lebih parahnya apabila banyak piutang yang sulit tertagih dan didukung penelitian terdahulu disimpulkan bahwa rasio likuiditas dari tahun 2014-2017 KUD Karya Muda ,desa Meninting tinggi berada dikisaran $209 \%>150 \%$.dan dari hasil laporan keuangan

http://ejurnal.binawakya.or.id/index.php/MBI 
bahwa tingkat piutang sangat besar, merupakan piutang anggota. Sehingga ini dapat berpengaruh terhadap SHU.(Suharti dkk, ;2018 :523-529) Oleh karena itu peneliti tertarik unruk memecahkan permasalahan ini dengan tujuan untuk mengetahui rasio kemampulabaan dari KUD Karya Muda, Desa Meninting Kecamatan Batu Layar kabupatn Lombok Barat, dalam menukur kinerja manajemen koperasi.

Dari hasil pengumpulan data diperoleh data pendahuluan/ untuk itu dapat disajikan pada tabel 1 berikut ini :

Tabel 1. Data Laba Operasi Total Aktiva, Pendapatan ,Pada KUD Karya Muda Desa Meninting Tahun 2014-2018

\begin{tabular}{|c|c|c|c|}
\hline Tahun & $\begin{array}{c}\text { Laba } \\
\text { operasi } \\
\text { (Rp) }\end{array}$ & $\begin{array}{c}\text { Total } \\
\text { Aktiva } \\
\text { (Rp) }\end{array}$ & $\begin{array}{c}\text { Pendapatan } \\
\text { (Rp) }\end{array}$ \\
\hline 2014 & 9.038 .430 & 605.440 .422 & 44.000 .285 \\
\hline 2015 & 4.875 .000 & 651.996 .540 & 47.924 .744 \\
\hline 2016 & 8.621 .375 & 658.501 .135 & 37.887 .500 \\
\hline 2017 & 4.434 .500 & 746.000 .798 & 38.468 .000 \\
\hline 2018 & 6.760 .625 & 744.364 .607 & 31.944 .400 \\
\hline
\end{tabular}

Sumber data primer diolah

Dari data tabel 1 maka dapat dilihat balaba operasi dari tahun 2014 samapi dengan tahun 018 adalah Rp.9.038.430 ; Rp. 4.875.000 ; Rp.Rp.8.621.375 ; Rp.4.434.500 ; Rp.6.360.625 .Setiap tahun terjadi fluktuasi. Dan data dari total aktiva dari tahun 2014 sampai dengan tahun 2018. Adalah : Rp.605.440.442 ; Rp.651.996.540 ; Rp. 658.501.135 ; Rp. 746.000 .798 ; Rp. 744.364.607.Setiap tahun berfluktuasi dan tahun 2014 naik tetapi tahun 2015 - 2016 meningkat, akan tetapi tahun 2017 ke tahun 2018 menurun.. Sedangkan pendapatan/ penjualan terus berfluktuasi juga yaitu dari tahun 2015 sampai dengan tahun 2018 adalah seperti berikut ini : Rp.44.000.285 ; Rp.47.924.770 ; Rp.37.887.500 ; Rp.38.468.00 ; Rp.31.944.400.

Berdasarkan fakta dan teori, untuk memecahkan permaalahan dalam pengukuran efektifitas kinerja manajemen koperasi maka dipergunakan rasio kemampulabaan atau rasio profitabilitas. Oleh karena itu peneliti, mengangkat judul yaitu : Rasio Kemampulabaan Dalam Mengukur Kinerja Manajemen Koperasi Pada KUD’KARYA MUDA ‘, Desa Meninting http://ejurnal.binawakya.or.id/index.php/MBI
Kecamatan Batu Layar kabupaten Lombok Barat Tahun 2014-2018

\section{METODE PENELITIAN}

Jenis Penelitian : Penelitian yang dilakukan adalah penelitian Deskriptif kuantitatif adalah penelitian untuk menganalisis satu variabel atau lebih variabel tanpa membuat perbandingan atau menghubungkan variabel tersebut dan disarakan pada data yang berbentuk angka. (Suliyanto:2009; 9\&12) Tujuan dari penelitian ini adalah untuk mengetahui efektifitas penggunaan modal usaha dalam memperoleh SHU dalam mengukur kinerja manajemen koperasi. Yaitu menganalisis rasio kemampulabaan dalam mengukur kinerja manajemen koperasi pada KUD "Karya Muda", desa Meninting Kecamatan Batu Layar kabupaten Lombok Barat Tahun 2014-2018..

Lokasi Penelitian yaitu pada KUD "KARYA MUDA", Jalan Raya Senggigi Desa Meninting, Kecamatan Batu Layar Kabupaten Lobok Barat.Penelitan ini dilaksanakan pada tanggal 2 Maret 2018, Dengat Surat Tugas No 32/STIE-45/III/2018 dari Ketua STIE 45 Mataram per tanggal 1 Maret 2018. Badan Hukum dari KUD ini dengan NO : 379 a. BH / XXII- tgl 15 Juni 1984. Ketua Pengurus Koperasi saat ini adalah bapak Drs. Suandi, M.Ak dan Sekretaris bapak Mukril Hakim serta bendahara ibu Mustimah.

Teknik pengumpulan data yaitu dengan wawancara dan dokumenter yaitu dilakukan dengan mendapat data dari hasil wawancara langsung atau tatap muka dengan manajer koperasi dan juga dengan cara pencatatan terhadap data-data keuangan berupa laporan keuangan yaitu Laporan Neraca dan Laporan Rugi/laba dari tahun 2014 sampai dengan tahu 2018. Dengan surat Tugas dari Pembantu Ketua I STIE 45 Mataram per tanggal 6 januari 2019 dengan no surat : /STIE-45/I/2019. Penelitian dilakukan bersama-sama teman dosen.

Jenis dan sumber data: data kuantitatif yaitu data yng diukur dan dihitung dengan satuan angka.berupa data keuangan dan persediaan yang ada pada usaha tahu ini. Sumber datnya adalah

Vol.13 No.9 April 2019

\section{Open Journal Systems}


data primer yaitu data yang dipeoleh langsung dari obyek penelitian.Dan data skunder adalah berupa data kualitatif yang didapat dari kajian pustaka sebagai pembanding dalam mengambil kesimpulan.

Prosedur analisis yang dipergunakan adalah analisis kualitatif adalah analisis yang berupa penjelasan untuk mendukung dan analisis kuantitatif yaitu : (Bambang Riyanto,2011; 35 \& JP.Sitanggang :2014 ; 20),( Abdul Halim2015;214)

Analisis rasio kemampulabaan adalah untuk mengukur smpai seberapa besar efektifitas manajemen dalam mengelola asset dan equity yang dimiliki prusahaan untuk menghasilkan laba.atau dipergunakan untuk mengukur kemampuan suatu perusahaan untuk menghasilkan laba selama periode tertentu dan dinyatakan dalam prosentase dan rumus yang digunakan adalah sebagai berikut :

1. Gross Profit ratio yaitu perbandingan antara gross profit dengan net sales dengan formula :

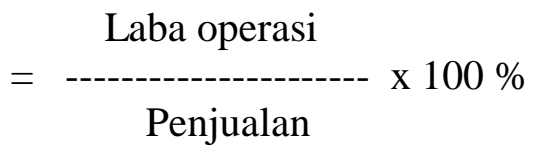

2. Return On Invesment ratio yaitu perbandingan antara earning before interest and tax dan total asset, dengan formula

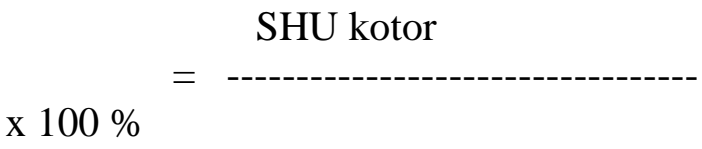

Total Aktiva

\section{HASIL DAN PEMBAHASAN Deskripsi Data}

Berdasarkan dari hasil pengumpulan data yaitu laporan keuangan KUD Karya Muda, Desa Meninting dari tahun 2014-2018 , maka dapat dsajikan data-data sebagai berikut pada tabel berikut ini :

\section{Vol.13 No.9 April 2019}

Tabel 2. Perkembangan laba operasi KUD KARYA MUDA ,Desa Meninting Tahun 20142018

\begin{tabular}{|c|c|c|c|}
\hline Tahun & $\begin{array}{c}\text { Laba } \\
\text { operasi } \\
\text { (Rp) }\end{array}$ & $\begin{array}{c}\text { Perekembangan } \\
\text { (Rp) }\end{array}$ & $\begin{array}{c}\text { Perkembang } \\
\text { an (\%) }\end{array}$ \\
\hline $\mathbf{2 0 1 4}$ & 9.038 .430 & & \\
\hline $\mathbf{2 0 1 5}$ & 4.875 .000 & $(4.163 .430)$ & $(46,06)$ \\
\hline $\mathbf{2 0 1 6}$ & 8.621 .375 & 3.746 .375 & 76,85 \\
\hline $\mathbf{2 0 1 7}$ & 4.434 .500 & $(4.186 .875)$ & $(48,56)$ \\
\hline $\mathbf{2 0 1 8}$ & 6.630 .625 & 2.196 .125 & 49,53 \\
\hline Total & 33.599 .930 & \multicolumn{2}{|l}{} \\
\cline { 1 - 2 } $\begin{array}{c}\text { Rata- } \\
\text { rata }\end{array}$ & 6.719 .986 & \multicolumn{2}{|l}{} \\
\cline { 1 - 2 } & &
\end{tabular}

Sumber data primer diolah

Dari tabel 2 diatas dapat dilihat perkembangan total laba operasi tahun 2014 2018 adalah sebesar Rp.33.599.930,00 dan ratarata laba operasi selama lima tahun terakhir adalah sebesar Rp.6.719.986,00. Dan perkembangan turn naiknya laba operasi adalah berfluktuasi yaitu tahun 2014 turun ke tahun 2015 sebesar Rp.4.163.430 atau 46,06 \%. Tahun 2016 naik sebesar Rp.3.746.375 atau 76,85 \% . tahun 2017 turun lagi sebesar p.4.186.875 atau 48,56\%. Dan tahun 2018 meningkat sebesar Rp.2.196.125 atau 49,53\%. Fluktuasi tersebut takibat dari naik turunnya pendapatan akan tetapi beban usaha tetap.

Tabel 3. Data Perkembangan Total Aktiva KUD KARYA MUDA, Desa meninting Tahun 20142018

\begin{tabular}{|c|c|c|c|}
\hline Tahun & $\begin{array}{c}\text { Total Aktiva } \\
(\text { Rp) }\end{array}$ & $\begin{array}{c}\text { Perkemban } \\
\text { gan }(\mathbf{R p )})\end{array}$ & $\begin{array}{c}\text { Perkemb } \\
\text { angan } \\
(\boldsymbol{\%})\end{array}$ \\
\hline 2014 & 605.508 .082 & & \\
\hline 2015 & 651.996 .540 & 46.488 .458 & 7,68 \\
\hline 2016 & 658.501 .135 & 6.504 .595 & 1,00 \\
\hline 2017 & 746.000 .798 & 87.499 .663 & 13,29 \\
\hline 2018 & 744.364 .607 & $(1.636 .191)$ & $(0,22)$ \\
\hline Total & $\mathbf{3 . 4 0 6 . 3 7 1 . 1 6 2}$ & \multicolumn{3}{|l}{} \\
\cline { 1 - 2 } $\begin{array}{c}\text { Rata- } \\
\text { rata }\end{array}$ & $\mathbf{6 8 1 . 2 7 4 . 2 3 2 , 4 0}$ & \multicolumn{1}{|l}{} \\
\cline { 1 - 2 } & &
\end{tabular}

Sumber data primer diolah

Dari perkembangan total aktiva koperasi dari tahun $2014-2018$ adalah sebesar Rp.3.406.371/162.Dan rata-ratanya adalah sebesar Rp.681.274.232,40. Sedangkan perkembangannya berfluktuasi walaupun tidak terlalu berarti . tahun 2014 ke tahun 2015 adalah 
sebesar Rp.Rp.46.488.458 atau 7,68 \%. Tahun 2015 ke tahun 2016 sebesar Rp.6.504.595 betambah atau $1,00 \%$.. Tahun 2016 ke tahun 2017 eningkat adalah sebesar Rp 87.499.663 atau $13,29 \%$ dan tahun 2017 ke tahun 2018 adalah menurun sebesar Rp.1/636.191 atau $0,22 \%$. Adanya terjadi kerugian yaitu pendapatan lebih kecil dari beaya beaya yang dikeluarkan koperasi sehinnga sisa hasil usaha rugi. Dan penagihan piutang tidak lancar tidak ada setoran yang berarti. Dampaknya SHU tahun berjalan rugi maka jumlah aktiva tahun 2018 menurun dari tahun 2017.

Tabel 4. Data Perkembngan Tingkat Pendapatan KUD KARYA MUDA Desa meninting Tahun 2014-2018

\begin{tabular}{|c|c|c|c|}
\hline $\begin{array}{c}\text { Tahu } \\
\text { n }\end{array}$ & $\begin{array}{c}\text { Pendapata } \\
\text { n ( Rp) }\end{array}$ & $\begin{array}{c}\text { Perkembanga } \\
\text { n (Rp) }\end{array}$ & $\begin{array}{c}\text { Perkemban } \\
\text { gan ( \%) }\end{array}$ \\
\hline $\mathbf{2 0 1 4}$ & 44.000 .285 & & \\
\hline $\mathbf{2 0 1 5}$ & 47.924 .744 & 3.924 .459 & 8,92 \\
\hline $\mathbf{2 0 1 6}$ & 37.887 .500 & $(10.037 .244)$ & $(20,94)$ \\
\hline $\mathbf{2 0 1 7}$ & 38.468 .000 & 580.500 & 1,53 \\
\hline $\mathbf{2 0 1 8}$ & 31.944 .400 & 6.523 .600 & 16,96 \\
\hline Total & $\begin{array}{c}\mathbf{2 0 0 . 2 2 4 . 9 2} \\
\mathbf{9}\end{array}$ & \multicolumn{2}{|c}{} \\
\cline { 1 - 2 } $\begin{array}{c}\text { Rata- } \\
\text { rata }\end{array}$ & $\begin{array}{c}\mathbf{4 0 . 0 4 4 . 9 8 5} \\
\mathbf{8 0}\end{array}$ & & \\
\cline { 1 - 2 } & &
\end{tabular}

Sumber data primer diolah

Berdasarkan dari data perkembangan pada tabel 4 dapat dilihat bahwa total tingkat pendapatan dari tahun 2014- 2018 totanya adala Rp.200.224.929,00 dan rata-ratanya adalah sebesar Rp.40.044.985,80. Dari lima tahun terakhir perkembangannya adalah berfluktuasi adanya penurunan pendapatan sebesar Rp.0/037.244,00 atau sebesar 20,94\%. Dan thun 2015 ke tahun 2016 adalah naik sebesar Rp. 3.924 .459 atau $8,92 \%$ dan tahun 2015 ke tahun 2016 menurun. Tahun 2016 ke tahun 2017 meningkat sebesar Rp.580.000 atau 1,53\%. Dan tahun 2017 ke tahun 2018 naik sebesar Rp.6.523.600 atau 16,96 \%.faktor yang menyebabkan menurun karena rendahnya tagihan piutang anggota.

Dan data perkembangan SHU kotor dapat disajikan pada tabel 5 berikut ini :
Tabel 5. Data Perkembangan SHU kotor KUD ARYA MUDA, Desa Meninting tahun 2014 2018

\begin{tabular}{|c|c|c|c|}
\hline $\begin{array}{c}\text { Tahu } \\
\text { n }\end{array}$ & $\begin{array}{l}\text { SHU } \\
\text { kotor } \\
\text { (Rp) }\end{array}$ & $\begin{array}{l}\text { Perkembang } \\
\text { an (Rp) }\end{array}$ & $\begin{array}{l}\text { Perkembang } \\
\text { an }(\%)\end{array}$ \\
\hline 2014 & $\begin{array}{c}44.000 .28 \\
8\end{array}$ & & \\
\hline 2015 & $\begin{array}{c}47.049 .77 \\
0\end{array}$ & $47,049,769$ & 1 \\
\hline 2016 & $\begin{array}{c}57.887 .00 \\
0\end{array}$ & $57,886,999$ & 1 \\
\hline 2017 & $\begin{array}{c}38.468 .00 \\
0\end{array}$ & $38,467,999$ & 1 \\
\hline 2018 & $\begin{array}{c}31.944 .40 \\
0\end{array}$ & $31,944,399$ & 1 \\
\hline Total & $\begin{array}{c}180,881,4 \\
96\end{array}$ & & \\
\hline $\begin{array}{c}\text { Rata- } \\
\text { rata }\end{array}$ & $\begin{array}{c}36,176,29 \\
9\end{array}$ & & \\
\hline
\end{tabular}

\section{Analisis Data}

\section{Analisis Gross profit Margin Ratio}

Berdasarkan dari data yang ada pada deskripsi data pada tabel 2 dan tabel 4 disajikan perhitungan rasio laba kotor atau gross profit margin ratio (GFMR) pada tabel 5 berikut ini :

Tabel 6. Perhitungan rario Gross Profit Margin KUD KARYA MUDA Desa Meninting Tahun $2014-2018$

\begin{tabular}{|c|c|c|c|}
\hline Tahun & $\begin{array}{c}\text { Laba } \\
\text { operasi } \\
(\mathbf{R p})\end{array}$ & $\begin{array}{c}\text { Pendapatan } \\
(\mathbf{R p})\end{array}$ & $\begin{array}{c}\text { GFMR } \\
(\mathbf{\%})\end{array}$ \\
\hline $\mathbf{2 0 1 5}$ & 9.038 .430 & 44.000 .285 & 20,54 \\
\hline $\mathbf{2 0 1 5}$ & 4.875 .000 & 47.924 .744 & 10,17 \\
\hline $\mathbf{2 0 1 6}$ & 8.621 .375 & 37.887 .500 & 22,75 \\
\hline $\mathbf{2 0 1 7}$ & 4.434 .500 & 38.468 .000 & 11,53 \\
\hline $\mathbf{2 0 1 8}$ & 6.630 .625 & 31.944 .400 & 41,51 \\
\hline $\begin{array}{c}\text { Rata- } \\
\text { rata } \\
\text { GFMR }\end{array}$ & & & 21,30 \\
\hline
\end{tabular}

Sumber data primer diolah

Dari hasil perhitungan pada tabel 5 diatas maka daptat dianalisis dan dilihat perkembangan rasio laba kotor KUD Karya muda Desa Meninting bahwa setiap tahun selama lima tahun terakhir dari tahun $2014-2018$, berfluktuasi yaitu sebagai berikut : 20,54 \% ; 10,17 \% ; 22,75\% :; $11,53 \% ; 41,51 \%$. Adanya fluktuasi dari shu kotor dan fluktuasi tingkat pendapatan. Rata-rata rasio historis sema lima tahun adalah 
$21,30 \%$.Sehingga ini akan berpengaruh terhadap turun naiknya rasio tersebut.Dilihat dari rata-rata historis rasio tersebut adalah bahwa tahun 2014 tidak efektif karena lebih rendah dari rata-rata sehingga dikatakan tidak efektif yaitu : 20,54\% $<21,30 \%$. Dan tidak efektif dadi tahun 2015 karena berada dibawah rata-rata. Tahun2016 adalah efetif karena berada diatas rata -rata. Yaitu 22,75\%>21,30\%. Tahun 2016 adalah tidak efektif berada di bawah rata-rata yaitu 11,53 $\%<21,30 \%$. Tahun 2018 dikatakan efektif karena berada diatas rata - rata yaitu $41,51 \%>$ $21,30 \%$. Tetapi rasio SHU kotor mempunyai kelemahan karena SHUnya belum mengurangi beaya-beaya operasional koperasi sehingga rasionyadapat dikatakan efektif. Dan dilihat dari tingkat suku bunga deposito Bank adalah sebesar $5,7 \%$ setahun artinya apabila uang tersebut di deposito maka akan lebih efektif daripada dikelola. Namun karena ini adalah uang dari anggota dan kopersi punya prinsip social oriented bertujuan untuk kesejahtraan anggota pada khususnya dan masyarakat pada umunya shingga ini sudah efektif.

\section{Return On Invesment Ratio (ROI)}

Berdasarkan dari data pada tabel 2 dan 3 maka dapat disajikan data untuk menghitung rasio return on investment pada tabel 6 berikut ini

Tabel 6. Perhitungan Rasio Return On Invesment Pdasa KUD KARYA Muda desa Meninting Tahun 2014-2018

\begin{tabular}{|c|c|c|c|}
\hline Tahun & $\begin{array}{c}\text { SHU kotor } \\
\text { (Rp) }\end{array}$ & Aktiva (Rp) & ROI ( \%) \\
\hline $\mathbf{2 0 1 4}$ & 44.000 .288 & 605.508 .082 & 7,27 \\
\hline $\mathbf{2 0 1 5}$ & 47.049 .770 & 651.996 .540 & 7,22 \\
\hline $\mathbf{2 0 1 6}$ & 57.887 .000 & 658.501 .135 & 8,79 \\
\hline $\mathbf{2 0 1 7}$ & 38.468 .000 & 746.000 .798 & 5,16 \\
\hline $\mathbf{2 0 1 8}$ & 31.944 .400 & 744.364 .607 & 4,29 \\
\hline $\begin{array}{c}\text { Rata- } \\
\text { rata } \\
\text { rasio } \\
\text { ROI }\end{array}$ & & & 5,97 \\
\hline
\end{tabular}

Sumber data primer diolah

Berdasarkan perhitunganrasio ROI pada tabel 6 diatas maka dapat dianalisis. Hasil perhitungan rasio ROI dari tahun $2014-2018$ adalah sebagai berikut : 7,27 \%; 7,22\%; 8,79\%;

Vol.13 No.9 April 2019
$5,16 \% ; 4,29 \%$ dan rata 5 tahun terakhir adalah sebesar 5,97\%. Dilihat dari rata -rata standar tingkat suku bunga deposito Bank yaitu 5,7\% per tahun artinya bahwa rasio koperasi lebih besar daripada rasio yang dijadikan standar maka rasio tersebut tidak efektif yaitu $5,97 \%>5,67 \%$. Variabel tersebut dipengaruhi oleh rendahnya SHU kotor yang diperoleh olh koperasi karena besarnya tingkat piutang dari anggota. Modal yang diinvestasikan untuk usaha dalam satu periode pengembaliannya efektif walaupun secara riil setiap tahun 2014 ke tahun 2015 adalah menurun dan meningkat tahun 2016 dan tahun 2017 dan tahun 2018 menurun . Ini disebabkan oleh SHU kotor yang berfluktuasi dan bahkan dapat dikatakan semakin menurun.

3. Interpretasi Data

Dari hasil analisis data maka dapat diinterpretasikan data tersebut sebagai berikut :

a. Rasio Gross Profit Margin tahun 2014 adalah sebesar 20,54 \%, artinya setiap Rp.1000 pendapatan m/penjualan enghasilkan Rp. 205,4; tahun 2015 aalah sebesar $10,17 \%$, artinya bahwa setiap Rp.1000 pendapatan /pnjualan Rp.101,7 ; tahun 2016 rasionya adalah sebesar $22,75 \%$, artinya ;.bahwa setiap Rp.1000 pendapatan menghasilkan SHU sebesar Rp.227,5 dan tahun 2017 rasionya sebesar 11,53 \$, artinya bahwa pendapatan dalam setahun menghasilkan SHU kotor sebesar Rp.115,3. Serta tahun 2018 rasionya adalah sebesar 41,51 \% , artinya pendapatan yang dikelola setiap Rp1.000 dapat menghasikan SHU kotor nenghasilkan Rp.410, 10. Dan rata-rata rasionya dalam lima tahun adalah sebesar $21,30 \%$, artinya bahwa setiap Rp.1000 pendapatan/penjualan menghasilkan SHU kotor sebesar Rp.200,30.Dan dapat dikatakan efektif karena berada diatas rata-rata tingkat suku Bunga deposito bank yang berlaku

b. Dari hasil rasio Return On Invesment pada KUD Karya Muda desa Meninting Kecamatan Batu Layar kabpaten Lombok

http://ejurnal.binawakya.or.id/index.php/MBI 
Barat tahu 2014-2018 adalah sebagai berikut : tahun 2014 sebesar 7,27 \% , artinya bahwa kemampuan dari modal yang diinvestasikan pada aktiva setiap Rp1000 untuk menghasilkan SHU kotor Rp 0,0727 dan tahun 2015 rasionya adalah sebesar 7,22\% artinya bahwa setiap Rp1000, menhhasilkan 0,0722 dan tahun 2016 sebesar 8,79 \% , artinya bahwa setiap Rp.1000 menghasilkan SHU kotor sebesar 0,0879. Tahun 2017 adalah sebesar $5,16 \%$, artinya pada setiap Rp.1000 aktiva yang diinvestasikan untuk menghasilkan SHU kotor sebesar Rp.0,0516. Rasio di Tahun 2018 adalah sebesar 5,29 \% artinya bahwa setiap Rp.1000 aktiva menghasilkan SHU kotor sebesar Rp, 0,0429. Serta rata-rata selama lima tahun terakhir rasionya adalah sebesar 5,97 \%, artinya bahwa setiap Rp.1000 keseluruhan aktiva yang diinvestasikan untuk menghasilkan SHU kotor adalah sebesar Rp. 0,0597. Dan dikatakan tidak efektif karena berada di bawah standar tingkat suku bunga deposito bank yang berlaku.

\section{PENUTUP}

\section{Kesimpulan}

Berdasarkan dari hasil dan pembahasan maka dapat di simpulkan bahwa rasio kemampulabaan untuk mengukur kinerja manajemen koperasi pada KUD KARYA MUDA Desa Meninting Kecamatan Batu Layar Kabupaten Lombok Barat sebagai berikut :

1. Rasio Gross profit Margin rata-rata adalah sebesar 21,30 \% dalam lima tahun terakhir yaitu tahun 2014 - 2018 , ini dikatakan efektif karena berada diatas standar yaitu 21,30\%>5,67\%.

2. Rasio Return On Invesment rata-rata adalah sebesar 5,97 \% dari tahun 2014 2018 , dikatakan efektif karena berada di bawah standar bank yaitu $5,97 \%<5,67$ $\%$.
Saran

Berdasarkan dari kesimpulan maka dapat disarankan kepada pihak manajemen dan Instansi terkait adalah sebagai berikut :

1. Diperlukan peningkatan keseimbangan, agar pengelolaan modal usaha dalam menghasilkan SHU yang lebih tinggi, agar rasio kemampulabaan koperasi lebih efektif

2. Pembinaan dari Pemerintah dan instansi terkait agar dilaksanakan lebih intensif dan kepada peneliti lain untuk menganalisis kinerja operasional manajemen.

\section{DAFTAR PUSTAKA}

[1] Abdul Halim, DR,SE,MM,Ak,2015, Manajemen Keuangan Bisnis Konsep dan Aplikasinya, Penerbit Mitra Wacana Media, Jakarta

[2] Bambang Riyanto, Prof, DR,2011,DasarDasar Pembelanjaan Perusahaan, Penerbit BPFE UGM, Yogyakarta

[3] JP.Sitanggang,DR,2014, Manajemen Keuangan Perusahaan Edisi 2, Penerbit Mitra wacana Media, Jakarta

[4] IGusti Putu Bagus Suastina \& I Gusti Ayu Oka Netrawati, 2016, Analisis Rasio Kinerja Keuangan KPRI Patut Patuh Patju Kabupaten Lombok Barat Tahun 2012-2015, Jurnal Media Bina Ilmiah, ISSN 1978-3787, Vol.10 No.8,Agustus 2016.

[5] Suharti \& I Gusti Ayu Oka Netrawati, 2018, Analisis Rasio Kewajiban Jangka Pendek Dalam Mengukur Kebijakan Keuangan Koperasi Pada KUD "Karya Muda "Di Desa Menining Kecamatan Batu Layar, Kabupaten Lombok Barat. , Jurnal Media Bina Ilmiah, ISSN 1978-3787 dan ISSN 2615 - 3505 , Vol.12. No.10, Mei 2018.

[6] Suliyanto,SE,MSi, 2015, Metode Riset Bisnis, Penerbit Andi, Yogyakarta 
HALAMAN INI SENGAJA DIKOSONGKAN 